\title{
Particle Size Distribution Dynamics Can Help Constrain the Phase State of Secondary Organic Aerosol
}

Yicong $\mathrm{He}^{1}$, Ali Akherati ${ }^{1}$, Theodora $\mathrm{Nah}^{2,3}$, Nga L. $\mathrm{Ng}^{4,5,6}$, Lauren A. Garofalo ${ }^{7}$, Delphine K. Farmer ${ }^{7}$, Manabu Shiraiwa ${ }^{8}$, Rahul A. Zaveri ${ }^{9}$, Christopher D. Cappa ${ }^{10}$, Jeffrey R. Pierce ${ }^{11}$, and Shantanu H. Jathar ${ }^{*}$

${ }^{1}$ Department of Mechanical Engineering, Colorado State University, Fort Collins, CO, USA

${ }^{2}$ School of Energy and Environment, City University of Hong Kong, Hong Kong, China

${ }^{3}$ State Key Laboratory of Marine Pollution, City University of Hong Kong, Hong Kong, China

${ }^{4}$ School of Chemical and Biomolecular Engineering, Georgia Institute of Technology, Atlanta, GA, USA

${ }^{5}$ School of Earth and Atmospheric Sciences, Georgia Institute of Technology, Atlanta, GA, USA

${ }^{6}$ School of Civil and Environmental Engineering, Georgia Institute of Technology, Atlanta, GA, USA

${ }^{7}$ Department of Chemistry, Colorado State University, Fort Collins, CO, USA

${ }^{8}$ Department of Chemistry, University of California, Irvine, Irvine, CA, USA

${ }^{9}$ Atmospheric Sciences and Global Change Division, Pacific Northwest National Laboratory, Richland, WA, USA

${ }^{10}$ Department of Civil and Environmental Engineering, University of California Davis, Davis, CA, USA

${ }^{11}$ Department of Atmospheric Science, Colorado State University, Fort Collins, CO, USA

*Correspondence to: Shantanu H. Jathar (shantanu.jathar@colostate.edu)

\section{S1 New Particle Formation}

In the nucleation experiments, SOA was formed through nucleation and growth of new particles. We used the scanning mobility particle sizer (SMPS) data to model the rate and timing of new particle formation. This was done by first calculating the linear change in the total suspended number concentration from the start of the nucleation event ( $\sim 10$ minutes after the start of the ozonolysis experiment) to the end of the nucleation event ( $\sim 35$ minutes after the start of the ozonolysis experiment) where the total suspended number concentration plateaued. This change in the number concentration was then divided by the time period over which nucleation occurred to calculate a nucleation rate in $\mathrm{cm}^{-3} \mathrm{~s}^{-1}$. The use of this nucleation rate in the SOM-TOMAS model simulations was able to accurately predict the observed change in total suspended number concentration over time (Figure $\mathrm{S} 1$ for $500 \mathrm{ppbv}_{3}$ experiment). The offline calculation of the nucleation rate described above did not account for losses of the new particles to the chamber walls or to coagulation. The good model-measurement agreement shown in Figure S1 suggests that neither of these loss processes were as important over the time scale for nucleation.

\section{S2 Chamber Wall Losses}


Loss of vapors of the model species to the chamber walls was modeled in SOM-TOMAS following the methods described in previous publications. ${ }^{1,2}$ Briefly, the first-order uptake of the vapors to the walls was assumed to be equal to $k_{w, \text { on }}$ and the release of vapors from the walls, $k_{w, \text { off }}$, was modeled using absorptive partitioning theory with the Teflon ${ }^{\circledR}$ wall serving as an absorbing mass with an effective mass concentration of $C_{w} \mathrm{mg} \mathrm{m}^{-3} . k_{w, \text { on }}$ for a model species was calculated using the following equation that assumes that the mass accommodation coefficient of the vapor with the wall was larger than $10^{-6.3}$

$k_{w, o n}=\frac{2}{\pi} \frac{A}{V} \sqrt{k_{e} D_{v}}$

Where $\mathrm{A} / \mathrm{V}$ is the surface area to volume ratio for the Teflon ${ }^{\circledR}$ chamber, $k_{e}$ is the coefficient of eddy diffusion, and $D_{v}$ is the gas-phase diffusion coefficient of the vapor molecule. $k_{w, \text { off }}$ was calculated using the following equation: ${ }^{4}$

$k_{w, o f f}=k_{w, o n} \frac{C^{*}}{C_{w}}$

Nah et al..$^{5}$ used a $k_{e}$ of $0.03 \mathrm{~s}^{-1}$ and a $k_{\text {vap,on }}$ of $6.1 \times 10^{-4} \mathrm{~s}^{-1}$ for the GTEC chamber. Based on the observations of Krechmer et al., ${ }^{6} C_{w}$ was varied with the $C^{*}$ of the model species, with higher values used for more volatile species (e.g., $C_{w}=10 \mathrm{mg} \mathrm{m}^{-3}$ for $C^{*}>10^{4} \mu \mathrm{g} \mathrm{m}^{-3}$ ) and vice versa (e.g., $C_{w}=0.016 \mathrm{mg} \mathrm{m}^{-3}$

for $C^{*}<1 \mu \mathrm{g} \mathrm{m}^{-3}$ ). Losses of particles to the chamber walls were modeled using the size-dependent loss rate, $\beta$ in $\mathrm{s}^{-1}$, determined in Nah et al. ${ }^{5} \beta$ was determined from analyzing number size distribution data gathered by the SMPS using an aerosol dynamics model that accounted for the influence of coagulation. ${ }^{7}$

\section{S3 Calculation of $D_{b}$ Based on the Predicted SOA Composition}

We used the semi-empirical approach described by Shiraiwa and coworkers ${ }^{8}$ to calculate the $D_{b}$ value from the model-predicted composition of SOA. First, we calculated the glass transition temperature $\left(T_{g}\right)$ for each model species as follows:

$T_{g, i}=A+B M_{i}+C M_{i}^{2}+D\left(O: C_{i}\right)+E M\left(O: C_{i}\right)$ 
Where $M_{i}$ is the molecular weight of the species $i\left(\mathrm{~g} \mathrm{~mol}^{-1}\right)$ and $O: C_{i}$ is the elemental oxygen-to-carbon ratio of species $i$. The coefficients have values of $A=-21.57(\mathrm{~K}), B=1.51\left(\mathrm{~K} \mathrm{~mol} \mathrm{~g}^{-1}\right), C=-1.7 \times 10^{-3}(\mathrm{~K}$ $\left.\mathrm{mol}^{2} \mathrm{~g}^{-2}\right), D=131.40(\mathrm{~K})$ and $E=-0.25\left(\mathrm{~K} \mathrm{~mol} \mathrm{~g}^{-1}\right)$. Next, we calculated the glass transition temperature of the SOA mixture as follows:

$T_{g, \text { org }}=\sum_{i=1}^{n} f_{i} T_{g, i}$

Where $n$ is the total number of model species and $f_{i}$ is the mass fraction of species $i$. The viscosity of the SOA was calculated using the following equation proposed by Angell: ${ }^{9}$

$\eta=\eta_{0} e^{\frac{D}{(I+D / 39.15) T / T \text { g.org }^{-1}}}$

Where $\eta_{0}$ is the viscosity of the fluid at infinite temperature $\left(10^{-5} \mathrm{~Pa} \cdot \mathrm{s}\right), D$ is the fragility parameter (10), ${ }^{10}$ and $T$ is the ambient temperature $(298 \mathrm{~K})$. Finally, the $D_{b}$ value was calculated using the fractional Stokes-Einstein equation as proposed by Evoy et al.: ${ }^{11}$

$D_{b}=\frac{k_{B} T}{6 \pi d \eta_{C}}\left(\frac{\eta_{C}}{\eta}\right)^{\xi}$

Where $\eta_{C}$ is the reference viscosity $\left(10^{-3} \mathrm{~Pa} \cdot \mathrm{s}\right), \xi$ is an empirically-determined exponent $(0.93), d$ is the effective molecular diameter of the model species $(0.7 \mathrm{~nm})$, and $k_{B}$ is the Boltzmann constant $\left(1.38 \times 10^{-23}\right.$ $\left.\mathrm{m}^{2} \mathrm{~kg} \mathrm{~s}^{-2} \mathrm{~K}^{-1}\right)$

\section{S4 Kelvin Ratio and Fuchs-Sutugin Correction Factor}

The Kelvin Ratio $(K R)$ was calculated as follows:

$K R=e^{\gamma M_{i} /\left(\rho R T D_{p, j}\right)}$

Where $\gamma$ is the surface tension $\left(0.025 \mathrm{~N} \mathrm{~m}^{-1}\right), \rho$ is the particle density in $\mathrm{kg} \mathrm{m}^{-3}, R$ is the universal gas constant $\left(8.314 \mathrm{~J} \mathrm{~mol}^{-1} \mathrm{~K}^{-1}\right), T$ is the ambient temperature $(298 \mathrm{~K})$, and $D_{p}$ is the particle diameter of size bin $j$ in $\mathrm{m}$. The Fuchs-Sutugin (FS) correction factor was calculated as follows: ${ }^{12}$

$F S=\frac{0.75 \alpha\left(1+K_{n}\right)}{K_{n}^{2}+K_{n}+0.283 K_{n} \alpha+0.75 \alpha}$ 
Where $K_{n}$ is the Knudsen number $\left(K_{n}=\frac{2 \lambda_{A B}}{D_{p, j}}\right), \alpha$ is the mass accommodation coefficient (assumed to be 1) and $\lambda_{A B}$ is the mean free path of the organic molecule in air in $\mathrm{m}$.

\section{S5 Derivation of $\boldsymbol{k}_{i, j}^{p}$ for Core-Shell Morphology}

We derived an analytical equation for $k_{i, j}^{p}$ for a core-shell morphology, following methods analogous to those presented in Zaveri et al. ${ }^{13}$ We started with the mass diffusion equation in a spherical particle in radial coordinates:

$\frac{\partial A}{\partial t}=D_{b}\left(\frac{\partial^{2} A}{\partial r^{2}}+\frac{2}{r} \frac{\partial A}{\partial r}\right)$

Where $A$ is the mass concentration of the diffusing species, $D_{b}$ is the diffusion coefficient in the particle phase, and $r$ is the radial position. For a particle with a solid core, the gradient of $A$ at the core surface is zero, and therefore the boundary conditions are:

$\frac{\partial A}{\partial r}\left(R_{c}, t\right)=0$

$A\left(R_{p}, t\right)=A_{s}$

$A(r, 0)=0$

Where $R_{c}$ is the core radius, $R_{p}$ is the particle radius, and $A_{s}$ is the concentration of the species at the particle surface, which is assumed to be constant. The solution to equation (S9), with boundary conditions listed in equations 10 through 12 , is: $^{14}$

$\frac{A}{A_{s}}=1+\frac{2 R_{p}}{r} \sum_{1}^{\infty} \frac{\left(\beta_{n}^{2}+L^{2}\right) \cdot \sin \left(\beta_{n}\left(r-R_{p}\right) /\left(R_{p}-R_{c}\right)\right)}{\beta_{n}\left(L+L^{2}+\beta_{n}^{2}\right)} \cdot e^{-\beta_{n}^{2} D_{b} t /\left(R_{p}-R_{c}\right)^{2}}$

Where $L=\left(R_{p}-R_{c}\right) / R_{c}$ and $\beta_{n}$ s are the successive members of the infinite number of solutions to $\beta_{n} \cot \left(\beta_{n}\right)+L=0$. This solution can be extended to include first-order chemical decay within the aerosol following the methods of Danckwerts, ${ }^{15}$ which yields:

$$
\begin{aligned}
& \frac{A}{A_{s}}=1+\frac{2 R_{p}}{r} \sum_{1}^{\infty} \frac{\left(\beta_{n}^{2}+L^{2}\right) \cdot \sin \left(\beta_{n}\left(r-R_{p}\right) /\left(R_{p}-R_{c}\right)\right) q^{2}}{\beta_{n}\left(L+L^{2}+\beta_{n}^{2}\right)\left(\beta_{n}^{2}+q^{2}\right)}+\frac{2 R_{p}}{r} \sum_{l}^{\infty} \frac{\left(\beta_{n}^{2}+L^{2}\right) \cdot \sin \left(\beta_{n}\left(r-R_{p}\right) /\left(R_{p}-R_{c}\right)\right)}{\beta_{n}\left(L+L^{2}+\beta_{n}^{2}\right)\left(\beta_{n}^{2}+q^{2}\right)} . \\
& e^{-\left(\beta_{n}^{2} D_{b} /\left(R_{p}-R_{c}\right)^{2}+k_{c}\right) t}
\end{aligned}
$$


Where $q=\left(R_{p}-R_{c}\right) \sqrt{k_{c} / D_{b}}$, where $k_{c}$ is the first-order chemical loss rate. Now, we can relate the bulkaverage concentration, $\underline{A}$, to the surface concentration $A_{s}$ :

$\frac{\underline{\underline{A}}}{A_{s}}=\frac{\int_{R_{c}}^{R} 4 \pi r^{2}\left(A / A_{s}\right) d r}{(4 / 3) \pi\left(R_{p}^{3}-R_{c}^{3}\right)}=Q-U$

Where $Q$ is a constant factor and $U$ is a transient factor, as shown below:

$Q=1+\frac{6 R_{p}\left(R_{p}-R_{c}\right)}{R_{p}^{3}-R_{c}^{3}} \sum_{1}^{\infty} \frac{\left(\beta_{n}^{2}+L^{2}\right) q^{2}\left(R_{c} \beta_{n} \cos \left(\beta_{n}\right)+\left(R_{p}-R_{c}\right) \sin \left(\beta_{n}\right)-\beta_{n} R_{p}\right)}{\beta_{n}^{3}\left(L+L^{2}+\beta_{n}^{2}\right)\left(\beta_{n}^{2}+q^{2}\right)}$

$U=\frac{6 R_{p}\left(R_{p}-R_{c}\right)}{R_{p}^{3}-R_{c}^{3}} \sum_{l}^{\infty} \frac{\left(\beta_{n}^{2}+L^{2}\right)\left(R_{c} \beta_{n} \cos \left(\beta_{n}\right)+\left(R_{p}-R_{c}\right) \sin \left(\beta_{n}\right)-\beta_{n} R_{p}\right)}{\beta_{n}\left(L+L^{2}+\beta_{n}^{2}\right)\left(\beta_{n}^{2}+q^{2}\right)} \cdot e^{-\left(\beta_{n}^{2} D_{b} /\left(R_{p}-R_{c}\right)^{2}+k_{c}\right) t}$

Following methods in Zaveri et al., ${ }^{13}$ we found the $k_{j}^{p}$ for a core-shell aerosol, assuming slow reaction.

$k_{j}^{p}=\frac{R_{p}^{3}-R_{c}^{3}}{3 R_{p}^{2}} \cdot \frac{k_{c} Q}{1-Q}$

Substituting $Q$ and taking the limit of $k_{c}$ to zero, we get

$k_{j}^{p}=\frac{R_{p}^{3}-R_{c}^{3}}{3 R_{p}^{2}} \cdot \frac{-D_{b}\left(R_{p}^{3}-R_{c}^{3}\right)}{6 R_{p}\left(R_{p}-R_{c}\right)^{3} \sum_{1}^{\infty}\left(\beta_{n}^{2}+L^{2}\right)\left(R_{c} \beta_{n} \cos \left(\beta_{n}\right)+\left(R_{p}-R_{c}\right) \sin \left(\beta_{n}\right)-\beta_{n} R_{p}\right) /\left(\beta_{n}^{5}\left(L+L^{2}+\beta_{n}^{2}\right)\right)}$

\section{S6 Application of the SOM-TOMAS Model to Seeded Experiments}

Results from application of the SOM-TOMAS model to the higher-seed-concentration $\left(\sim 3000 \mu \mathrm{m}^{2} \mathrm{~cm}^{3}\right)$ $\alpha$-pinene ozonolysis experiment with $500 \mathrm{ppbv} \mathrm{O}_{3}$ are presented in Figure $\mathrm{S} 10$. Note that for the seeded experiments, we used a formulation of the particle-side mass transfer coefficient $\left(k_{i, j}^{p}\right)$ derived specifically for the core-shell case (Section S5). Similar to the nucleation experiments, a unique set of SOM parameters $\left(p_{f, 1-4}, \Delta L V P\right)$ was developed for each prescribed $D_{b}$ value and these produced good agreement with the time-varying SOA mass concentrations, as shown in Figure S10(a). SOM parameters from these fits are tabulated in Table S3. These SOM parameters produced a nearly-identical number size distribution 3 hours after the start of the ozonolysis experiment, all of which agreed reasonably well with the measured number size distribution (Figure $\mathrm{S} 10(\mathrm{~b})$ ). The use of different $D_{b}$ values produced a similar evolution in the number size distribution because, unlike in the nucleation simulations, bulk diffusion 
limitations had little to no influence on the size-dependent partitioning of SOA. The reason for this effect is explained below.

The suspended ammonium sulfate seed concentrations were still $\sim 3$ times the suspended SOA mass concentrations at the end of the experiment and hence the maximum SOA coatings at the end of the experiment were still quite thin (e.g., a 30\% increase in mass results in a $10 \%$ increase in particle diameter or radius). For instance, output from the SOM-TOMAS model (from any of the simulations for the seeded experiments) indicated that the SOA coating varied between 10 and $20 \mathrm{~nm}$ for the particle size range of $70-1000 \mathrm{~nm}$ that accounted for $95 \%$ of the SOA mass at the end of the experiment (Figure S11(b)). The coating thickness varied with particle size because the SOA mass condensed as per the Fuchs-corrected surface area, which shifted the SOA mass size distribution to smaller sizes with respect to the seed mass size distribution (Figure S11(a)). The relative uniformity in the SOA coating thickness with particle size meant that the length scales and timescales for bulk diffusion were nearly identical between the different particle sizes. Hence, in contrast to the nucleation simulations where the growth rates varied significantly between the particle sizes, simulations with the seeded experiments resulted in little to no variation in the growth of the different particle sizes across a range of $D_{b}$ values. The model predictions of SOA O:C for the different $D_{b}$ values in the seeded experiment (Figure S10(c)) were much more variable than those seen for the nucleation experiment, but the predictions lay well within the uncertainty of the measurements. Overall, these results suggest that the technique used to constrain $D_{b}$ in the nucleation experiment is unlikely to work with the seeded experiment where the SOA coating thickness is much smaller than the solid core radius. A similar analysis was performed for experiments where the initial seed was smaller than that presented in Figure S10 (Figure S12), yet the findings were nearly identical to those presented here.

We ran the SOM-TOMAS model using the optimal parameters developed in the nucleation experiment to predict the SOA formation in the seeded experiment. These results are shown as a solid red curve in 
Figure S10. These parameters seemed to reasonably reproduce the SOA O:C, and number size distribution but overestimated the SOA mass concentration by slightly less than $30 \%$. The overestimation in the SOA mass concentration is very likely due to experiment-to-experiment variability in the nucleation and seeded experiments since both were performed identically, within experimental variability, except for the use of the seed. 
Table S1: Details on the instrumentation used to perform measurements during the $\alpha$-pinene ozonolysis experiments.

\begin{tabular}{|l|l|l|}
\hline $\begin{array}{l}\text { Species/Data } \\
\text { Measured }\end{array}$ & Instrument & Notes \\
\hline$\alpha$-pinene & $\begin{array}{l}\text { Gas Chromatograph-Flame } \\
\text { Ionization Detector } \\
\text { (GC-FID; Agilent 7890A) }\end{array}$ & NA \\
\hline $\mathrm{O}_{3}$ & $\begin{array}{l}\text { Gas Analyzer } \\
\text { (Teledyne T400) }\end{array}$ & NA \\
\hline $\mathrm{NO}_{\mathrm{x}}$ & $\begin{array}{l}\text { Gas Analyzer } \\
\text { (Teledyne 200EU) }\end{array}$ & NA \\
\hline $\begin{array}{l}\text { Particle size } \\
\text { distribution }\end{array}$ & $\begin{array}{l}\text { Scanning Mobility Particle Sizer } \\
\text { (SMPS, TSI) }\end{array}$ & $\begin{array}{l}\text { Used to determine size-dependent particle wall } \\
\text { loss rates and SOA mass concentrations }\end{array}$ \\
\hline $\begin{array}{l}\text { Bulk aerosol mass } \\
\text { and composition }\end{array}$ & $\begin{array}{l}\text { High-Resolution Aerosol Mass } \\
\text { Spectrometer } \\
\text { (HR-AMS; Aerodyne Research, Inc.) }\end{array}$ & $\begin{array}{l}\text { Processed with SQUIRREL v1.63 and PIKA } \\
\text { vitermine O:C }\end{array}$ \\
\hline
\end{tabular}


Table S2: SOM parameters determined from fitting the SOA mass concentration in the nucleation experiment with $500 \mathrm{ppbv}_{3}$ for different prescribed $\mathrm{D}_{b}$ values. The last row contains the optimal fit where the SOA mass concentration and number size distribution were both used to fit the SOM parameters and $D_{b}$.

\begin{tabular}{|c|c|c|c|c|c|c|}
\hline $\boldsymbol{D}_{\boldsymbol{b}}\left(\mathbf{c m}^{\mathbf{2}} \mathbf{s}^{-\mathbf{1}}\right)$ & $\boldsymbol{\Delta L V P}$ & $\boldsymbol{f}_{\text {HOM }}$ & $\boldsymbol{p}_{\boldsymbol{f} 1}$ & $\boldsymbol{p}_{\boldsymbol{f} 2}$ & $\boldsymbol{p}_{\boldsymbol{f} 3}$ & $\boldsymbol{p}_{\boldsymbol{f} 4}$ \\
\hline $10^{-6}$ & 1.860 & 0.034 & 0.234 & 0.570 & 0.000 & 0.161 \\
\hline $10^{-14}$ & 2.127 & 0.034 & 0.000 & 0.857 & 0.000 & 0.109 \\
\hline $10^{-15}$ & 1.514 & 0.034 & 0.309 & 0.209 & 0.214 & 0.234 \\
\hline $10^{-16}$ & 1.750 & 0.034 & 0.253 & 0.463 & 0.001 & 0.248 \\
\hline $10^{-17}$ & 2.014 & 0.034 & 0.309 & 0.209 & 0.214 & 0.235 \\
\hline $10^{-19}$ & 2.486 & 0.034 & 0.266 & 0.169 & 0.265 & 0.266 \\
\hline${ }^{*} 3.4 \times 10^{-15}$ & 1.555 & 0.034 & 0.245 & 0.286 & 0.270 & 0.165 \\
\hline
\end{tabular}


Table S3: SOM parameters determined from fitting the SOA mass concentration in the seeded experiment with $500 \mathrm{ppbv}_{3}$ for different prescribed $D_{b}$ values.

\begin{tabular}{|c|c|c|c|c|c|c|}
\hline $\boldsymbol{D}_{\boldsymbol{b}}\left(\mathbf{c m}^{2} \mathbf{s}^{-1}\right)$ & $\boldsymbol{\Delta L V P}$ & $\boldsymbol{f}_{\boldsymbol{H O M}}$ & $\boldsymbol{p}_{\boldsymbol{f}}$ & $\boldsymbol{p}_{\boldsymbol{f} 2}$ & $\boldsymbol{p}_{f 3}$ & $\boldsymbol{p}_{f 4}$ \\
\hline $10^{-6}$ & 1.902 & 0.034 & 0.000 & 0.854 & 0.001 & 0.110 \\
\hline $10^{-14}$ & 1.918 & 0.034 & 0.104 & 0.750 & 0.000 & 0.112 \\
\hline $10^{-15}$ & 2.027 & 0.034 & 0.146 & 0.718 & 0.000 & 0.102 \\
\hline $10^{-16}$ & 2.266 & 0.034 & 0.000 & 0.902 & 0.001 & 0.063 \\
\hline $10^{-17}$ & 2.740 & 0.034 & 0.001 & 0.964 & 0.000 & 0.001 \\
\hline $10^{-19}$ & 2.552 & 0.034 & 0.063 & 0.665 & 0.126 & 0.112 \\
\hline
\end{tabular}




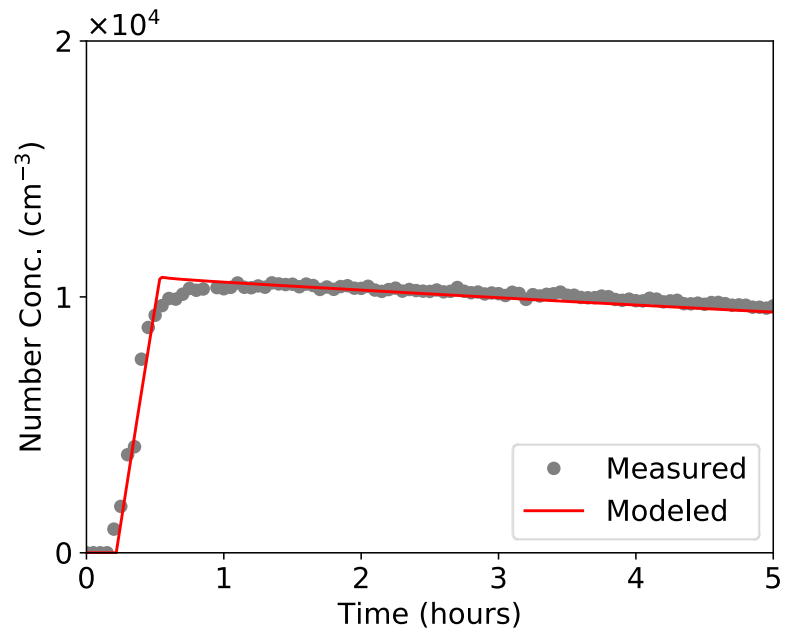

Figure S1: Modeled and measured total particle number concentrations in the nucleation experiment with 500 ppbv $\mathrm{O}_{3}$. 


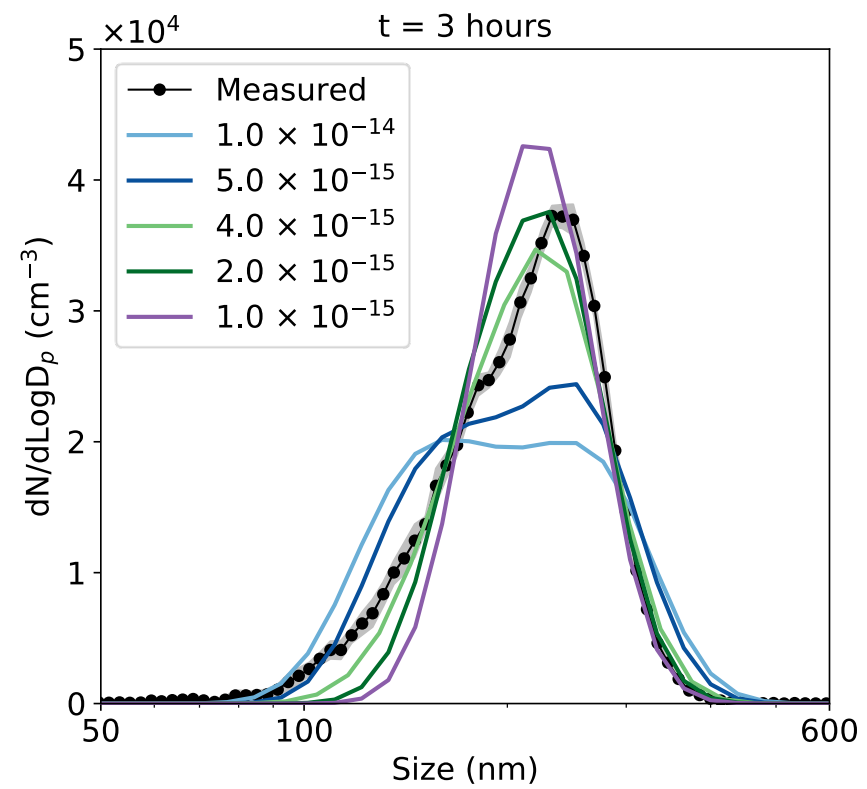

Figure S2: Results from the SOM-TOMAS model for number size distribution at 3 hours compared to measurements for a range of prescribed $D_{b}\left(\mathrm{~cm}^{2} \mathrm{~s}^{-1}\right)$ values. Results are for the $500 \mathrm{ppbv} \mathrm{O}_{3}$, nucleation experiment. The grey band depicts $\pm 1 \sigma$. 

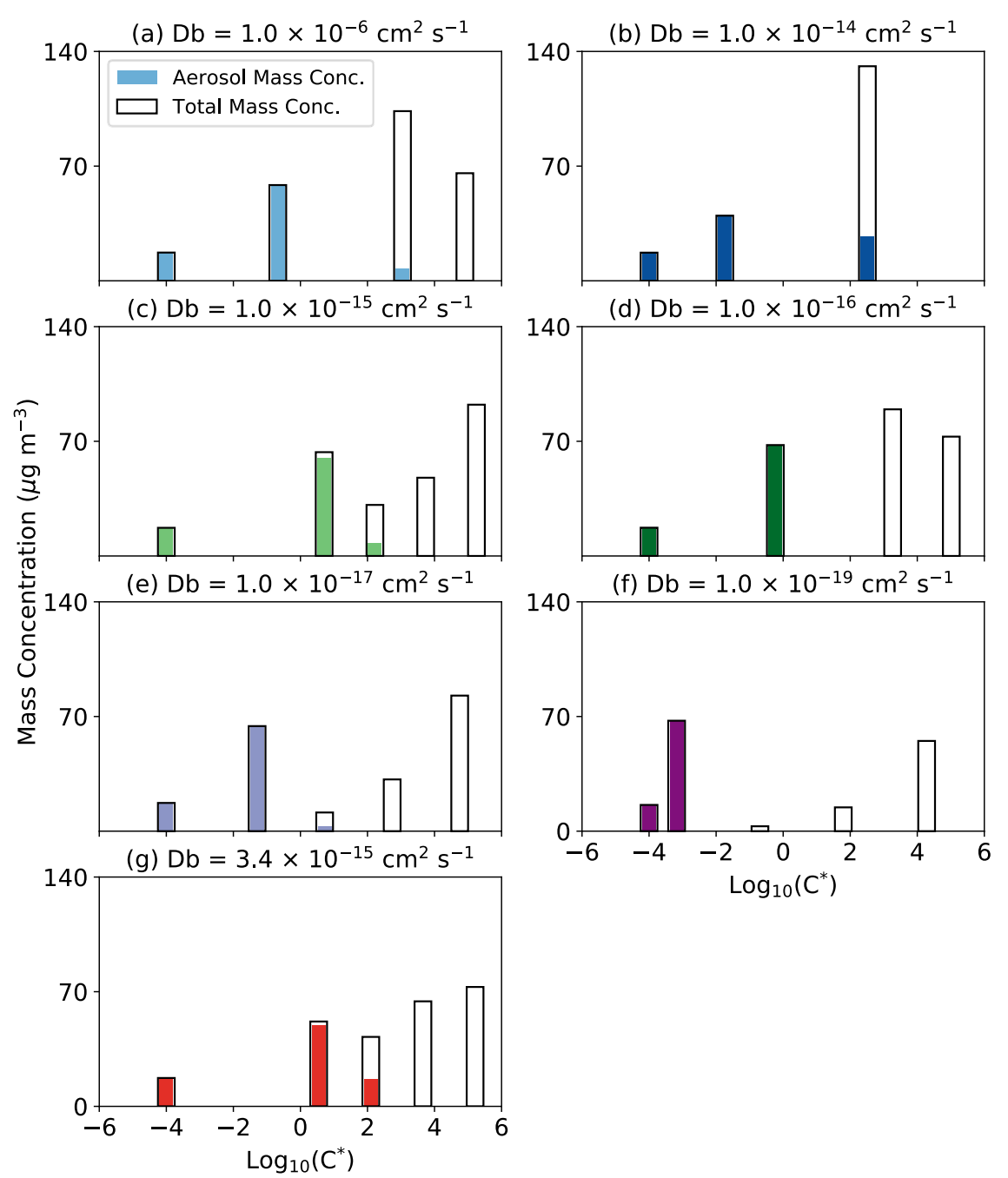

Figure S3: Model-predicted volatility distributions of SOA from the simulations performed for the 500 ppbv $\mathrm{O}_{3}$, nucleation experiment at different $D_{b}$ values. All volatility distributions are at 3 hours after the start of the ozonolysis experiment. 

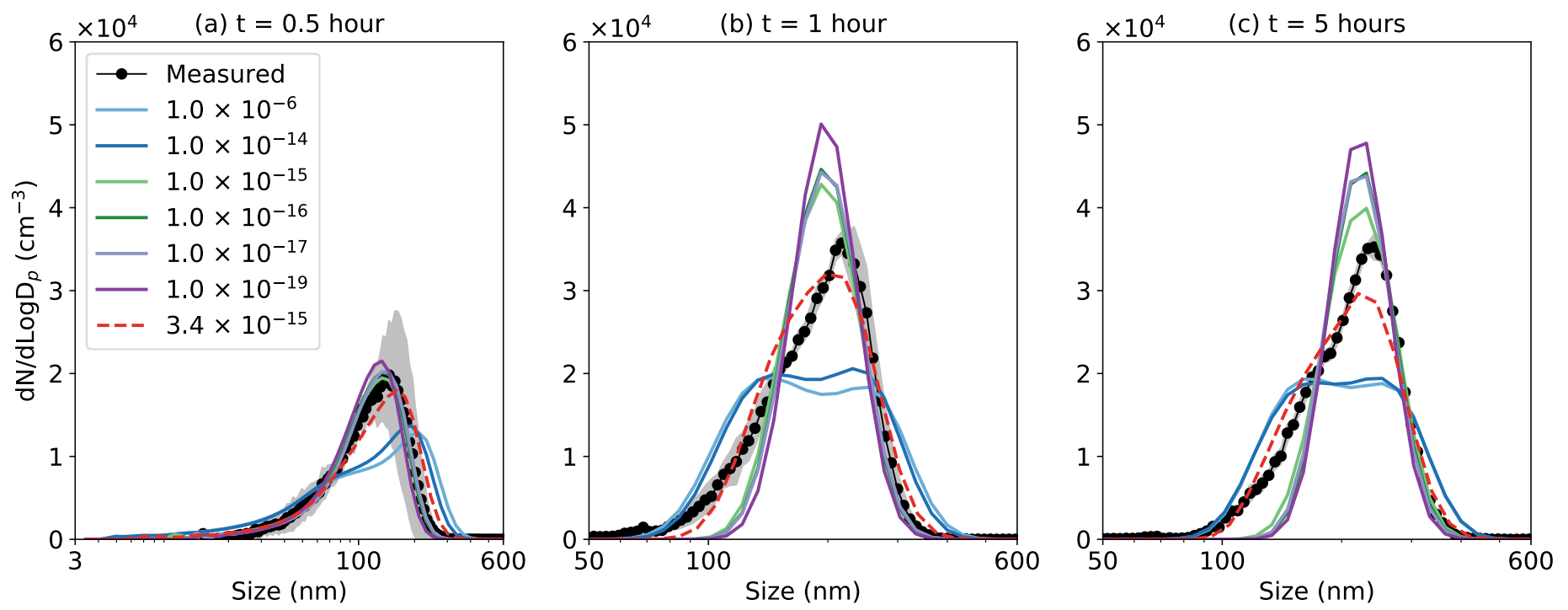

Figure S4: Results from the SOM-TOMAS model for number size distribution at (a) 0.5, (b) 1, and (c) 5 hours compared to measurements for a range of prescribed $D_{b}\left(\mathrm{~cm}^{2} \mathrm{~s}^{-1}\right)$ values. Results are for the 500 ppbv $\mathrm{O}_{3}$, nucleation experiment. The grey band depicts $\pm 1 \sigma$. 
(a)

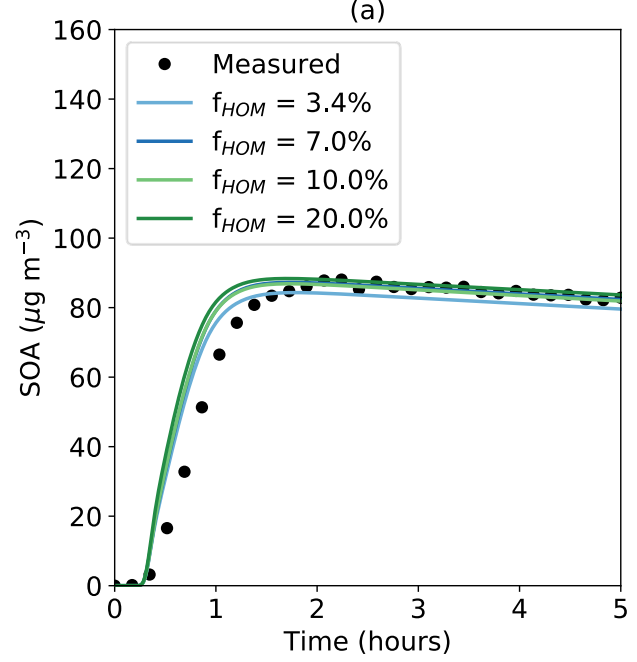

(b) $t=3$ hours

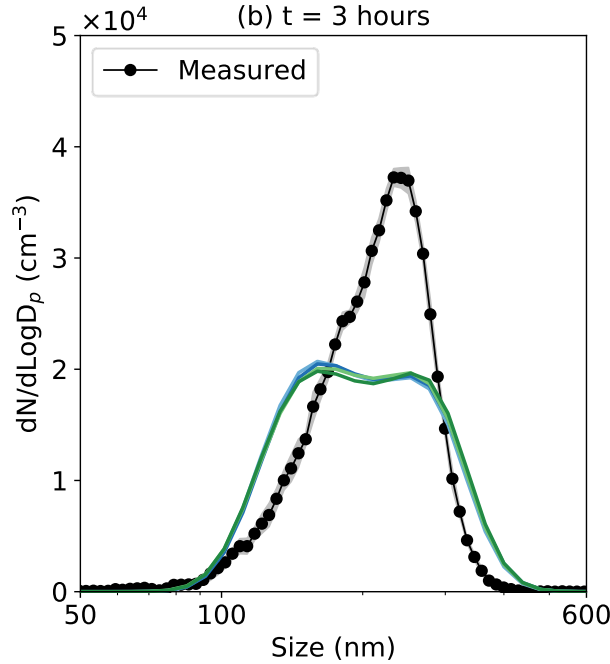

(c)

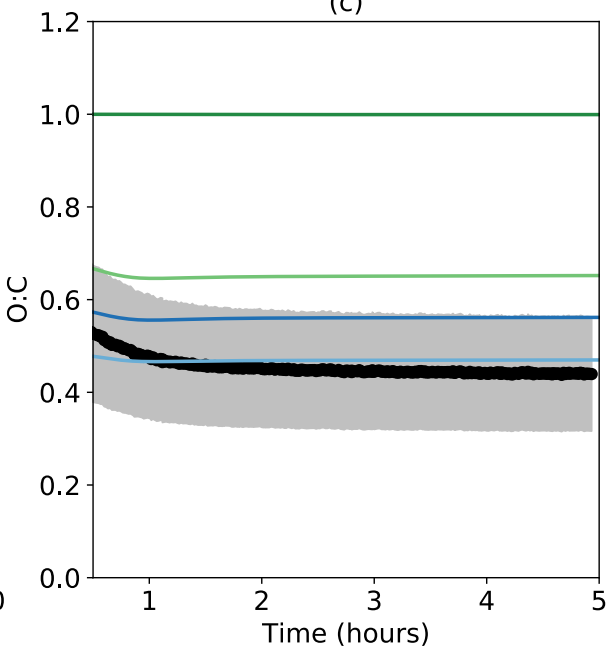

Figure S5: Results from the SOM-TOMAS model for (a) SOA mass concentration, (b) number size distribution at 3 hours, and (c) O:C ratio compared to measurements. Results are for the $500 \mathrm{ppbv} \mathrm{O}_{3}$, nucleation experiment. All simulations used a liquid-like $D_{b}$ of $10^{-6} \mathrm{~cm}^{2} \mathrm{~s}^{-1}$ with different molar yields for HOMs. The O:C data are only shown 30 minutes after the start of the experiment because the O:C measurements are fairly uncertain in the first 30 minutes when the SOA mass concentrations are quite low. The grey band in the panels (b) and (c) depicts $\pm 1 \sigma$. 
(a)

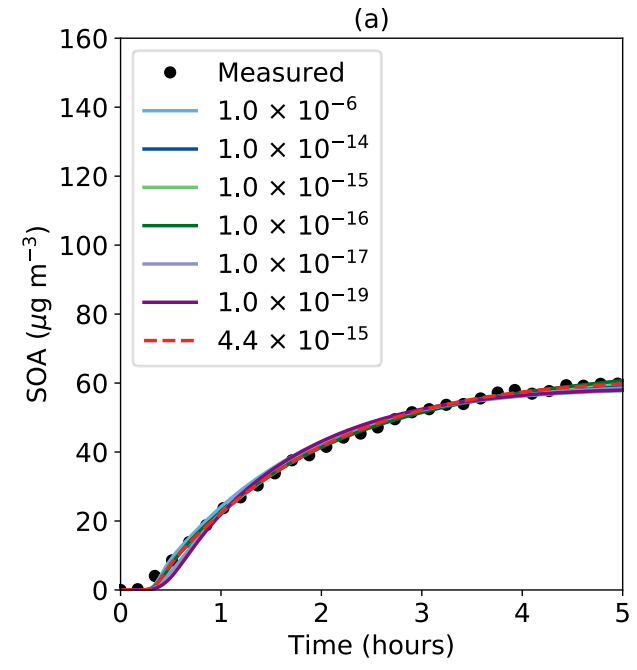

(b) $t=3$ hours

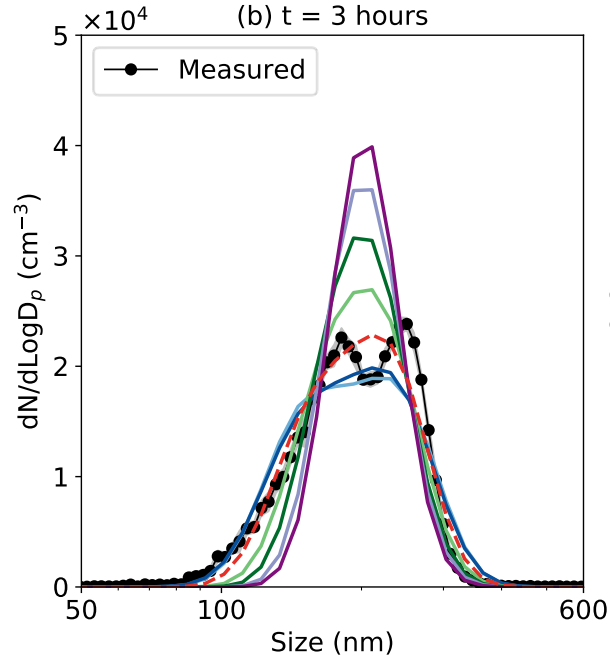

(c)

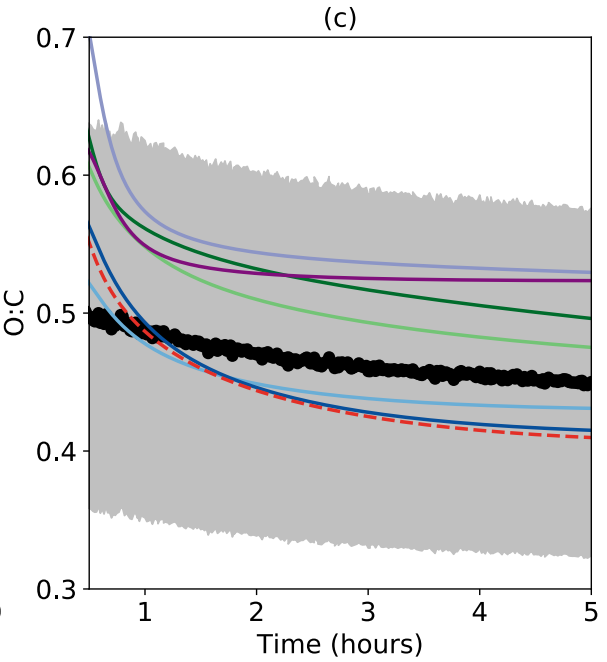

Figure S6: Results from the SOM-TOMAS model for (a) SOA mass concentration, (b) number size distribution at 3 hours, and (c) O:C ratio compared to measurements for a range of prescribed $D_{b}\left(\mathrm{~cm}^{2} s\right.$ $\left.{ }^{1}\right)$ values. Results are for the $100 \mathrm{ppbv} \mathrm{O}_{3}$, nucleation experiment. The dashed red line shows model predictions from the optimal fit when constrained to both the SOA mass concentration and number size distribution. The O:C data are only shown 30 minutes after the start of the experiment because the O:C measurements are fairly uncertain in the first 30 minutes when the SOA mass concentrations are quite low. The grey band in panels (b) and (c) depicts $\pm 1 \sigma$. 
(a)

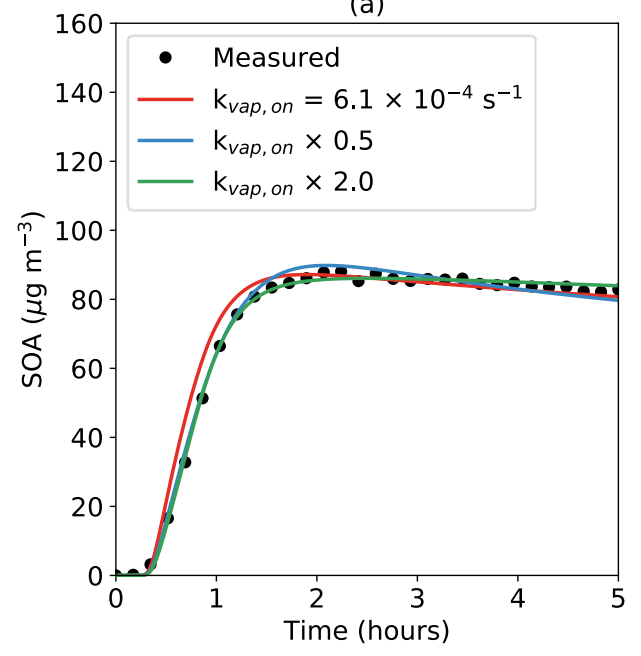

(b) $t=3$ hours

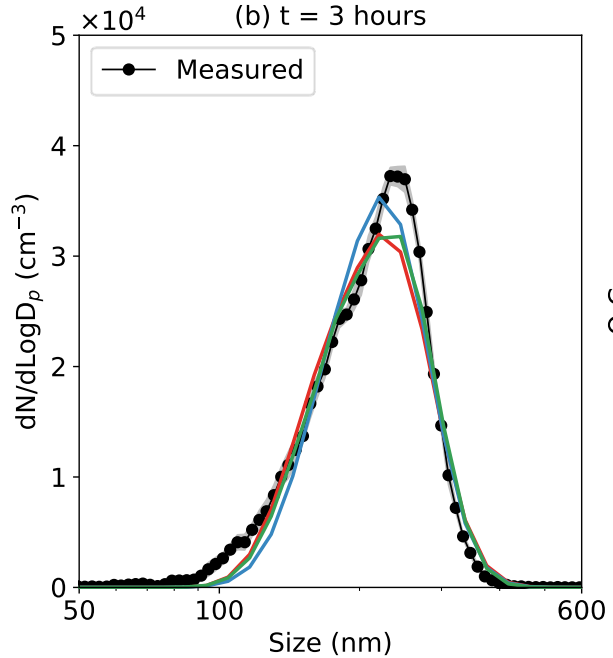

(c)

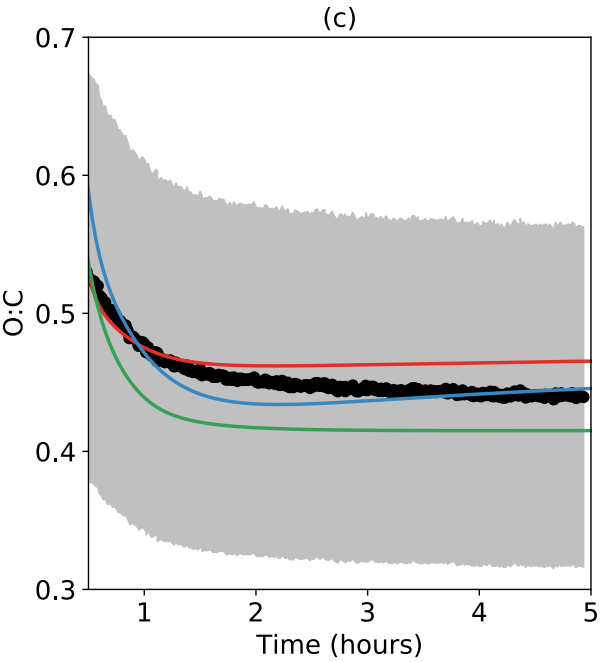

Figure S7: Results from simulations performed to assess sensitivity in the optimal $D_{b}$ for uncertainty in the vapor wall loss rate $\left(k_{v a p, o n}\right)$. Results are for the $500 \mathrm{ppbv} \mathrm{O}_{3}$, nucleation experiment. The grey band in panels $(b)$ and (c) depicts $\pm 1 \sigma$. The optimal $D_{b}$ for the $k_{\text {vap on }} \times 0.5$ and $k_{\text {vap on }} \times 2.0$ were $2.7 \times 10^{-15}$ and $7.1 \times 10^{-15} \mathrm{~cm}^{2} \mathrm{~s}^{-1}$. 
(a)

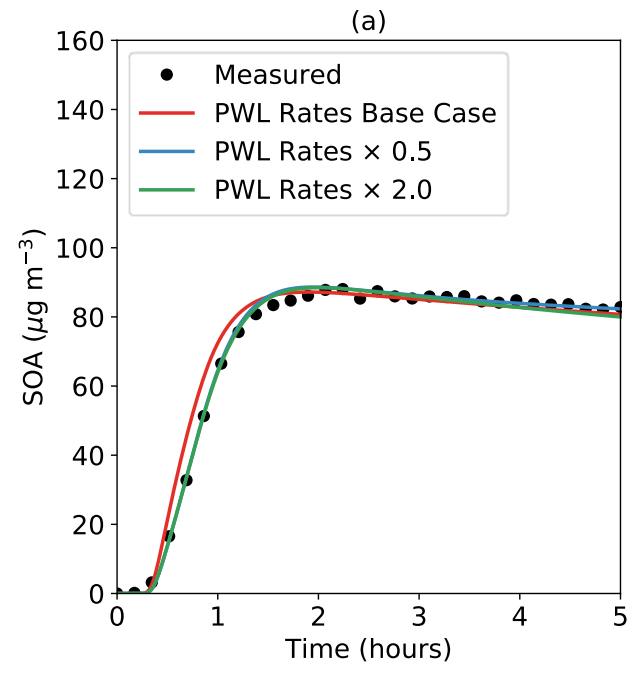

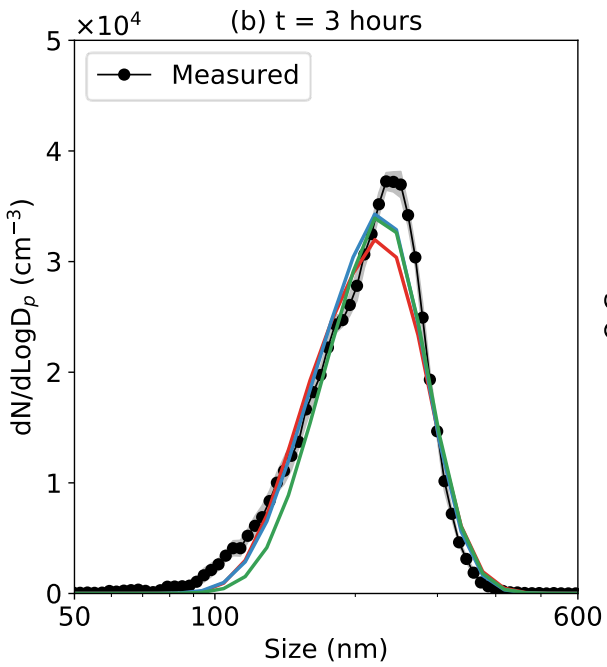

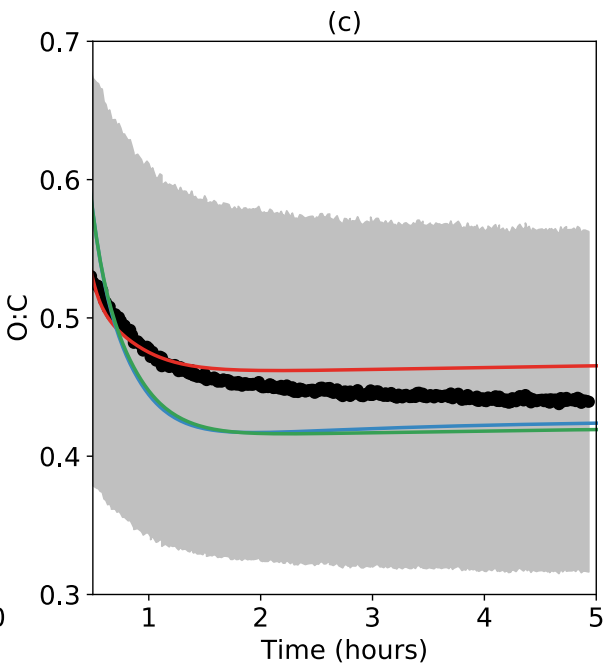

Figure S8: Results from simulations performed to assess sensitivity in the optimal $D_{b}$ for uncertainty in the size-dependent particle wall loss rate ( $P W L$ ). Results are for the $500 \mathrm{ppbv} \mathrm{O}_{3}$, nucleation experiment. The grey band in panels (b) and (c) depicts $\pm 1 \sigma$. The optimal $D_{b}$ for the $P W L \times 0.5$ and $P W L \times 2.0$ were $4.5 \times 10^{-15}$ and $3.9 \times 10^{-15} \mathrm{~cm}^{2} \mathrm{~s}^{-1}$. 
(a)

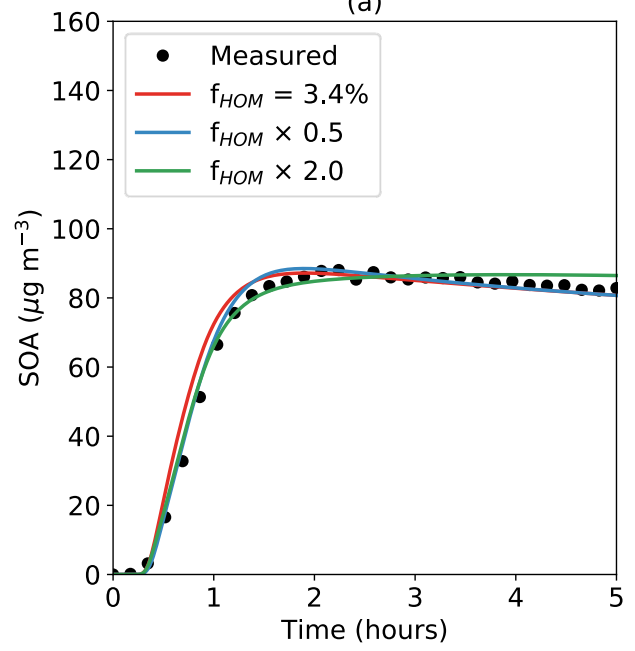

(b) $t=3$ hours

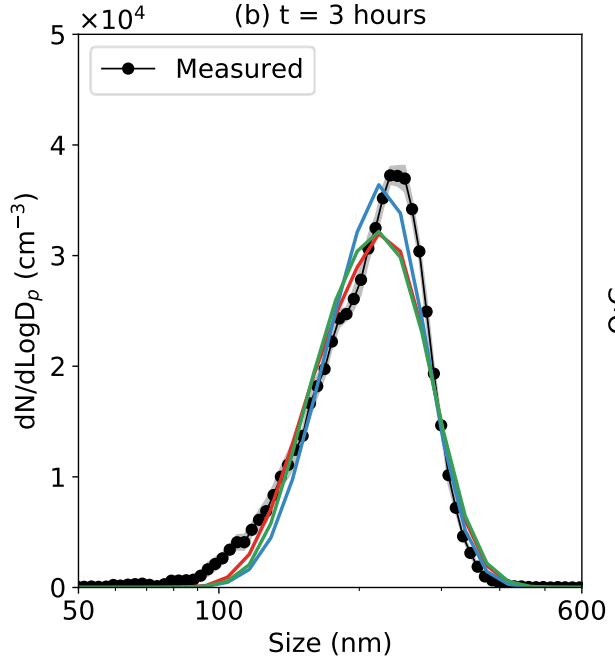

(c)

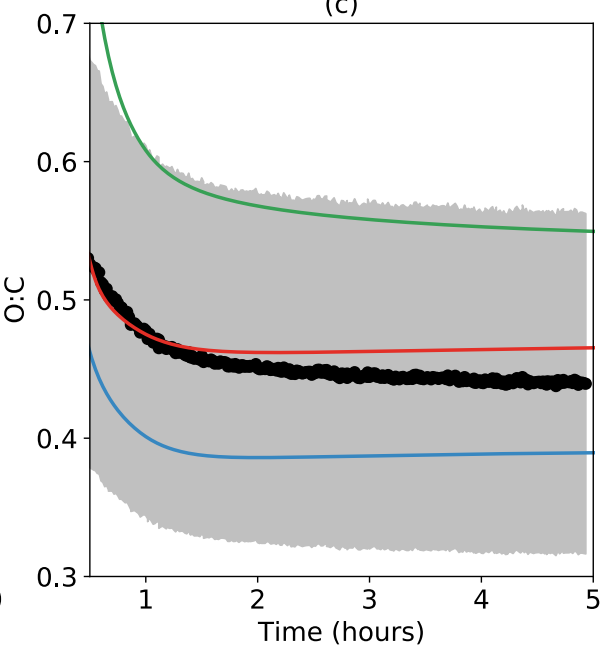

Figure S9: Results from simulations performed to assess sensitivity in the optimal $D_{b}$ for uncertainty in the molar yield for $\mathrm{HOM}\left(f_{\mathrm{HOM}}\right)$. Results are for the $500 \mathrm{ppbv} \mathrm{O}_{3}$, nucleation experiment. The grey band in panels (b) and (c) depicts $\pm 1 \sigma$. The optimal $D_{b}$ for the $f_{H O M} \times 0.5$ and $f_{H O M} \times 2.0$ were $3.9 \times 10^{-15}$ and $1.4 \times 10^{-15} \mathrm{~cm}^{2} \mathrm{~s}^{-1}$. 
(a)

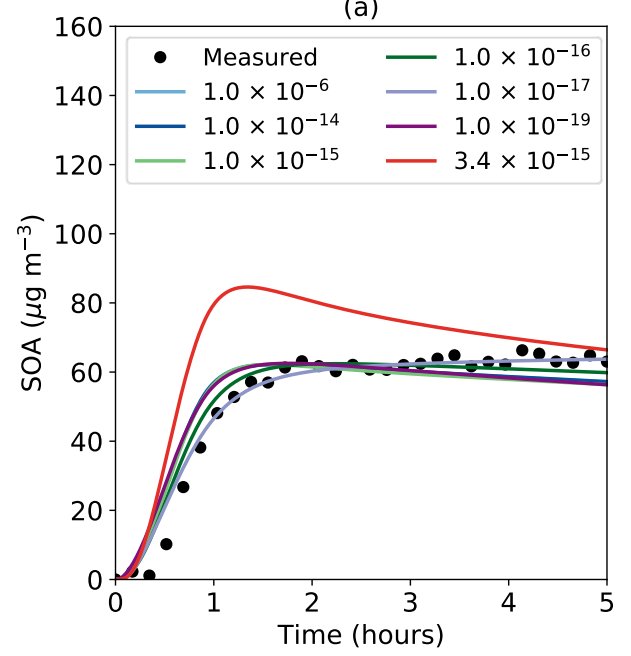

(b)

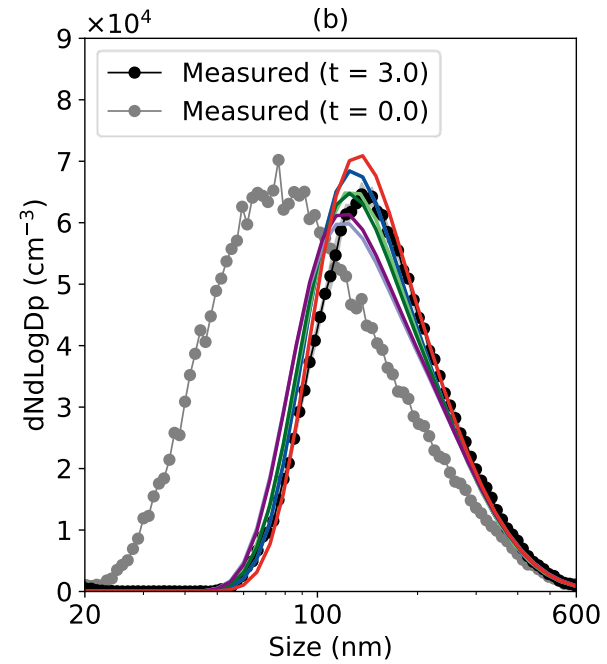

(c)

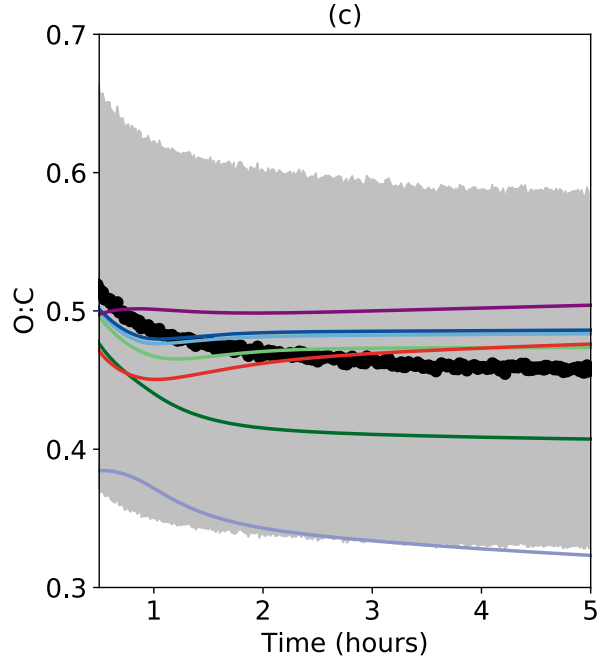

Figure S10: Results from the SOM-TOMAS model for (a) SOA mass concentration, (b) number size distribution at 3 hours, and (c) O:C ratio compared to measurements for a range of prescribed $D_{b}\left(\mathrm{~cm}^{2} \mathrm{~s}\right.$ $\left.{ }^{1}\right)$ values. Results are for the $500 \mathrm{ppbv} \mathrm{O}_{3}$, higher-seed-concentration $\left(\sim 3000 \mathrm{\mu m}^{2} \mathrm{~cm}^{3}\right)$ experiment. The solid red line shows model predictions from the optimal fit from Figure 1. The O:C data are only shown 30 minutes after the start of the experiment because the O:C measurements are fairly uncertain in the first 30 minutes when the SOA mass concentrations are quite low. The grey band in the panels (b) and (c) depicts $\pm 1 \sigma$. 
(a)

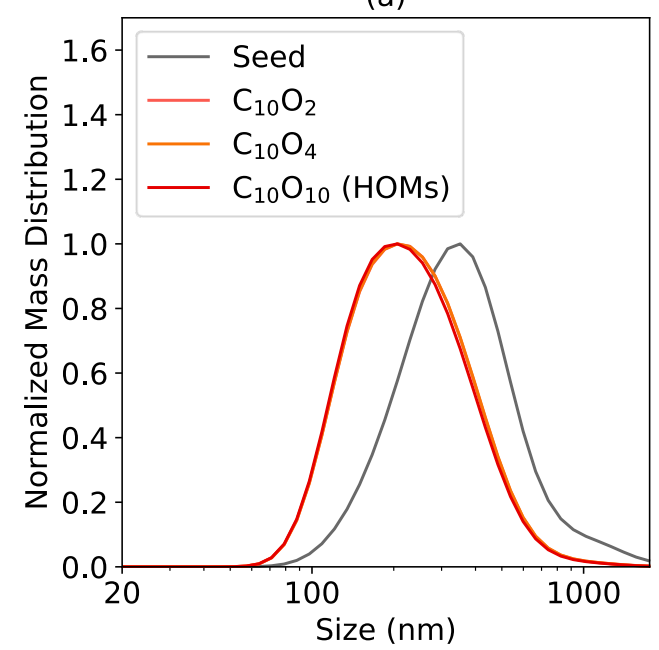

(b)

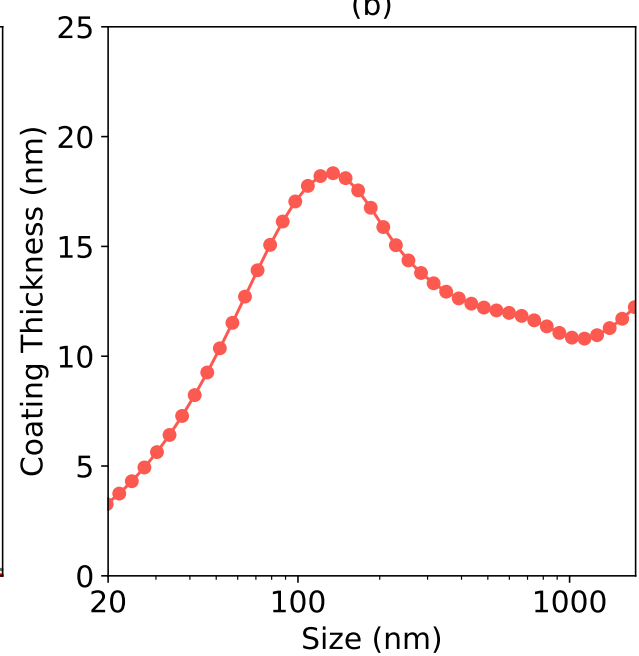

Figure S11: (a) Normalized mass size distributions for the ammonium sulfate seed and the three most abundant SOA model species at 3 hours after the start of the experiment. (b) SOA coating thickness as a function of particle size at the end of the experiment. Results are for the $500 \mathrm{ppbv} \mathrm{O}_{3}$, higher-seedconcentration $\left(\sim 3000 \mu^{2} \mathrm{~cm}^{3}\right)$ experiment. 
(a)

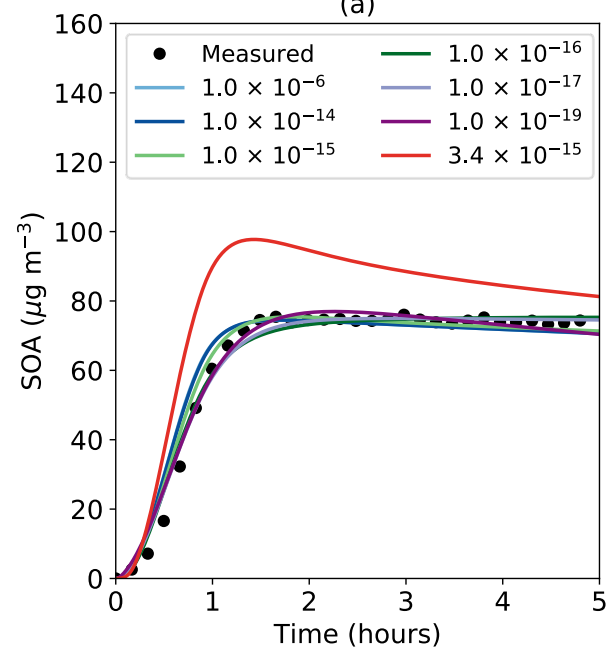

(b)

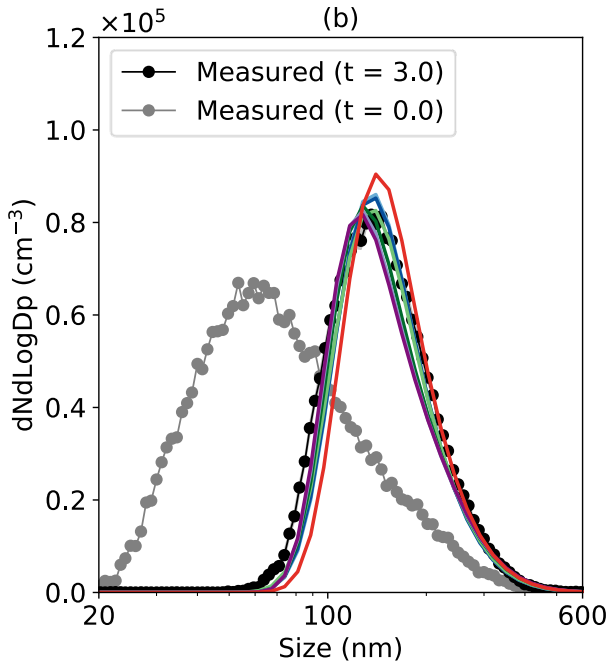

(c)

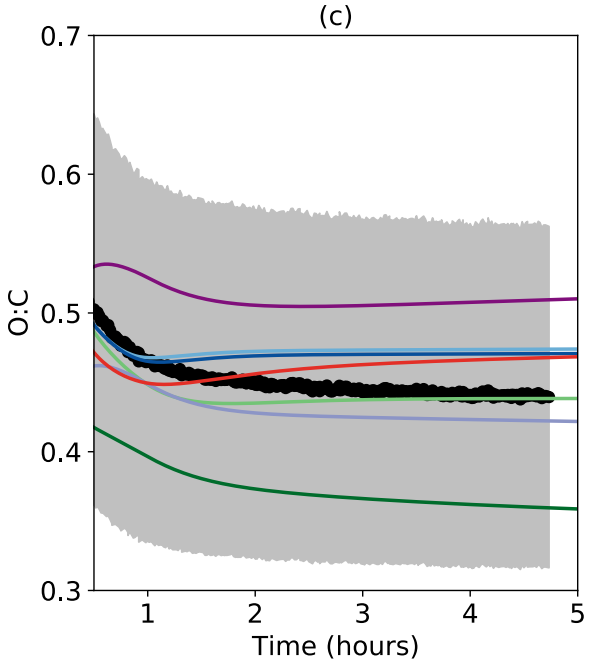

Figure S12: Results from the SOM-TOMAS model for (a) SOA mass concentration, (b) number size distribution at 3 hours, and (c) O:C ratio compared to measurements for a range of prescribed $D_{b}\left(\mathrm{~cm}^{2} \mathrm{~s}^{-}\right.$ $\left.{ }^{1}\right)$ values. Results are for the $500 \mathrm{ppbv} \mathrm{O}_{3}$, lower-seed-concentration $\left(\sim 1000 \mathrm{\mu m}^{2} \mathrm{~cm}^{3}\right)$ experiment. The solid red line shows model predictions from the optimal fit from Figure 1. The O:C data are only shown 30 minutes after the start of the experiment because the $O: C$ measurements are fairly uncertain in the first 30 minutes when the SOA mass concentrations are quite low. The grey band in the panels (b) and (c) depicts $\pm 1 \sigma$. 
(a)

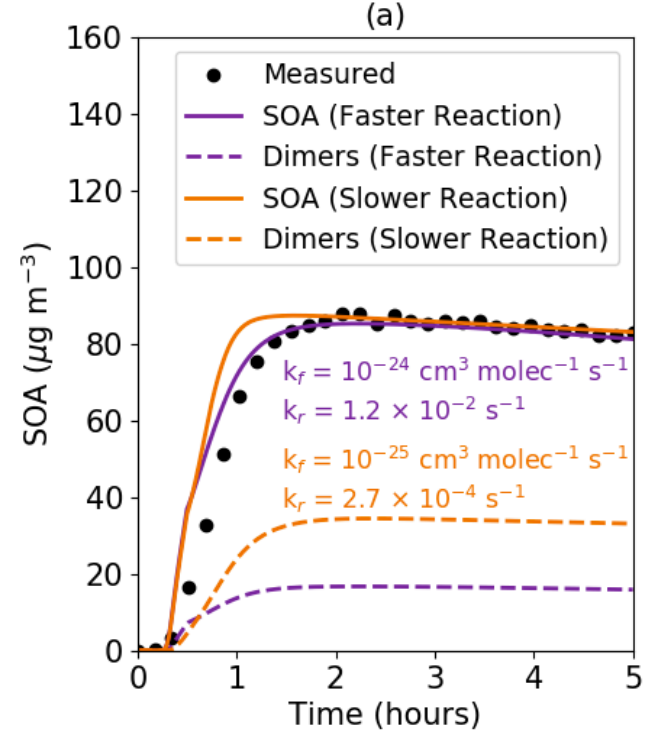

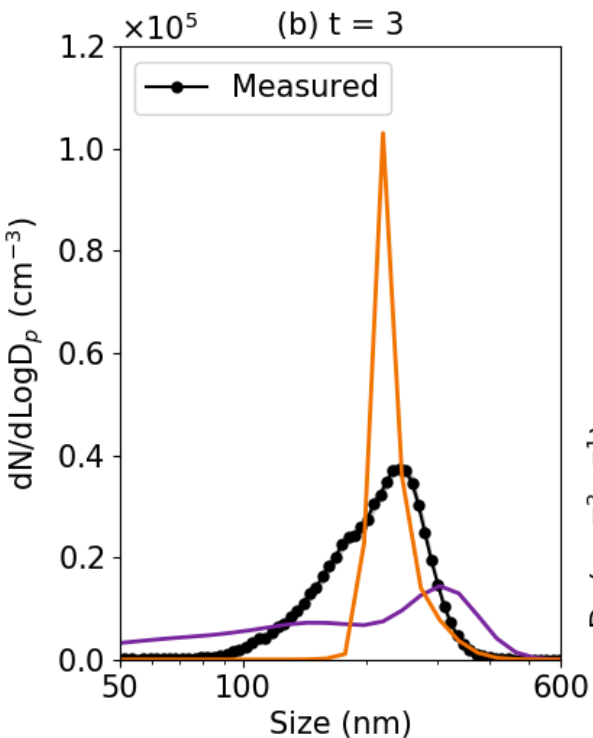

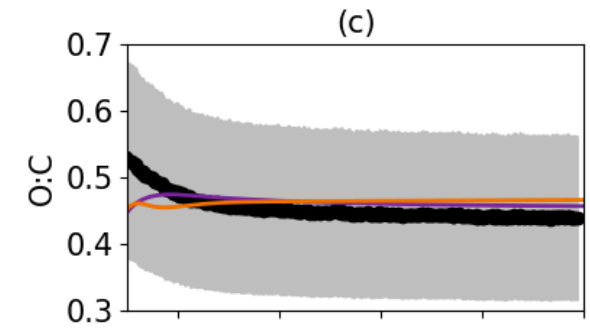

(d)

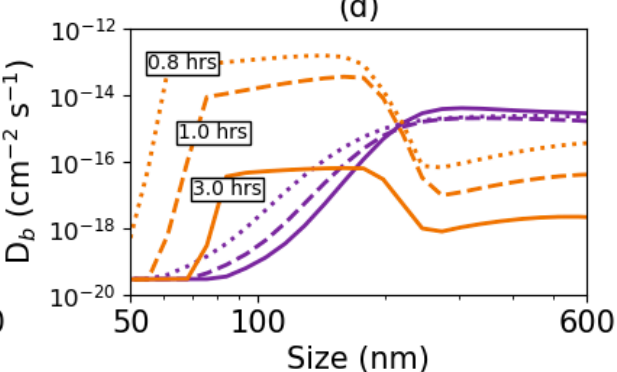

Figure S13: Results from the size-dependent, endogenous- $D_{b}$ version of the SOM-TOMAS model for (a) $S O A$ mass concentration, (b) number size distribution at 3 hours, and (c) O:C ratio compared to measurements. Model predictions of the size- and time-varying $D_{b}$ are shown in panel (d). Results are for the $500 \mathrm{ppbv}_{3}$, nucleation experiment. Both the slower-reacting (orange lines) and faster-reacting (purple lines) cases use the SOM parameters from the optimal Db fit in Figure 1 ( $p_{f}, 1-4, \Delta L V P$, $f_{H O M}=3.4 \%$ ) but with different oligomer formation and dissociation rates. The $O: C$ data are only shown 30 minutes after the start of the experiment because the O:C measurements are fairly uncertain in the first 30 minutes when the SOA mass concentrations are quite low. The grey band in panels (b) and (c) depict $\pm 1 \sigma$. 


\section{References}

(1) He, Y.; King, B.; Pothier, M.; Lewane, L.; Akherati, A.; Mattila, J.; Farmer, D. K.; McCormick, R. L.; Thornton, M.; Pierce, J. R.; Volckens, J.; Jathar, S. H. Secondary Organic Aerosol Formation from Evaporated Biofuels: Comparison to Gasoline and Correction for Vapor Wall Losses. Environ. Sci. Process. Impacts 2020, 22 (7), 1461-1474.

(2) Akherati, A.; He, Y.; Coggon, M. M.; Koss, A. R.; Hodshire, A. L.; Sekimoto, K.; Warneke, C.; de Gouw, J.; Yee, L.; Seinfeld, J. H.; Onasch, T. B.; Herndon, S. C.; Knighton, W. B.; Cappa, C. D.; Kleeman, M. J.; Lim, C. Y.; Kroll, J. H.; Pierce, J. R.; Jathar, S. H. Oxygenated Aromatic Compounds Are Important Precursors of Secondary Organic Aerosol in Biomass-Burning Emissions. Environ. Sci. Technol. 2020, 54 (14), 8568-8579.

(3) McMurry, P. H.; Grosjean, D. Photochemical Formation of Organic Aerosols: Growth Laws and Mechanisms. Atmospheric Environment (1967). 1985, pp 1445-1451.

(4) Matsunaga, A.; Ziemann \$, P. J. Gas-Wall Partitioning of Organic Compounds in a Teflon Film Chamber and Potential Effects on Reaction Product and Aerosol Yield Measurements. Aerosol Sci. Technol. 2010, 44 (10), 881-892.

(5) Nah, T.; McVay, R. C.; Zhang, X.; Boyd, C. M.; Seinfeld, J. H.; Ng, N. L. Influence of Seed Aerosol Surface Area and Oxidation Rate on Vapor Wall Deposition and SOA Mass Yields: A Case Study with $\alpha$-Pinene Ozonolysis. Atmos. Chem. Phys. 2016, 16 (14), 9361-9379.

(6) Krechmer, J. E.; Pagonis, D.; Ziemann, P. J.; Jimenez, J. L. Quantification of Gas-Wall Partitioning in Teflon Environmental Chambers Using Rapid Bursts of Low-Volatility Oxidized Species Generated in Situ. Environ. Sci. Technol. 2016, 50 (11), 5757-5765.

(7) Pierce, J. R.; Engelhart, G. J.; Hildebrandt, L.; Weitkamp, E. A.; Pathak, R. K.; Donahue, N. M.; Robinson, A. L.; Adams, P. J.; Pandis, S. N. Constraining Particle Evolution from Wall Losses, Coagulation, and Condensation-Evaporation in Smog-Chamber Experiments: Optimal Estimation Based on Size Distribution Measurements. Aerosol Science and Technology. 2008, pp 1001-1015.

(8) Shiraiwa, M.; Li, Y.; Tsimpidi, A. P.; Karydis, V. A.; Berkemeier, T.; Pandis, S. N.; Lelieveld, J.; Koop, T.; Pöschl, U. Global Distribution of Particle Phase State in Atmospheric Secondary Organic Aerosols. Nat. Commun. 2017, 8, 15002.

(9) Angell, C. A. Formation of Glasses from Liquids and Biopolymers. Science 1995, 267 (5206), 19241935.

(10) DeRieux, W.-S. W.; Li, Y.; Lin, P.; Laskin, J.; Laskin, A.; Bertram, A. K.; Nizkorodov, S. A.; Shiraiwa, M. Predicting the Glass Transition Temperature and Viscosity of Secondary Organic Material Using Molecular Composition. Atmos. Chem. Phys. 2018, 18 (9), 6331-6351.

(11) Evoy, E.; Maclean, A. M.; Rovelli, G.; Li, Y.; Tsimpidi, A. P.; Karydis, V. A.; Kamal, S.; Lelieveld, J.; Shiraiwa, M.; Reid, J. P.; Bertram, A. K. Predictions of Diffusion Rates of Large Organic Molecules in Secondary Organic Aerosols Using the Stokes-Einstein and Fractional Stokes-Einstein Relations. Atmos. Chem. Phys. 2019, 19 (15), 10073-10085.

(12) Pandis, S. N.; Seinfeld, J. H. Atmospheric Chemistry and Physics: From Air Pollution to Climate Change; Wiley, 2006.

(13) Zaveri, R. A.; Easter, R. C.; Shilling, J. E.; Seinfeld, J. H. Modeling Kinetic Partitioning of Secondary Organic Aerosol and Size Distribution Dynamics: Representing Effects of Volatility, Phase State, and Particle-Phase Reaction. Atmos. Chem. Phys. 2014, 14 (10), 5153-5181.

(14) Carslaw, H. S.; Jaeger, J. C. Conduction of Heat in Solids; Clarendon Press, 1986.

(15) Danckwerts, P. V. Absorption by Simultaneous Diffusion and Chemical Reaction into Particles of Various Shapes and into Falling Drops. Trans. Faraday Soc. 1951, 47 (0), 1014-1023. 